\title{
Variation from Cytopathogenic Biotype to Non-Cytopathogenic Biotype is Correlated with the Deletion of Cellular Sequence from Bovine Viral Diarrhea Viruses
}

\author{
Shigeyuki NAKAMURA, Kenichi SAKAMOTO'), Yoshihiro SAKODA ${ }^{1)}$, Tomoaki SHIMAZAKI, Yoshimitsu INOUE, \\ Nobuo OGAWA, and Akio FUKUSHO ${ }^{1) *}$ \\ National Veterinary Assay Laboratory, 1-15-1 Tokura, Kokubunji, Tokyo 185 and 'National Institute of Animal Health, Department of \\ Exotic Diseases, 6-20-1 Josui-honcho, Kodaira, Tokyo 187, Japan
}

(Received 22 July 1996/Accepted 7 January 1997)

\begin{abstract}
Non-cytopathogenic (NCP) viruses of bovine viral diarrhea (BVD) virus were detected at a low ratio by the reverse plaque formation method from virus samples after several plaque clonings of cytopathogenic (CP) BVD viruses; NADL and Osloss strains. This phenomenon suggests that the NCP BVD viruses are produced at a low ratio during the propagation of CP BVD viruses in vitro. To investigate the differences between the parent CP BVD virus and the NCP BVD virus as a real progeny, the regions flanking the insertion of cellular mRNA in the p125 domain of NADL and Osloss strains were amplified by RT-PCR and cloned into pGEM 3Z plasmid vector, and then sequenced. Consequently, it was confirmed that sequences of cellular mRNA insertion of CP BVD viruses, NADL and Osloss strains, were completely and exactly deleted from the NCP BVD viruses which were real progeny of CP BVD viruses, NADL and Osloss strains. These results suggest that NCP BVD viruses may revert from CP biotype to NCP biotype by the deletion of cellular mRNA insertion in the viral genome of CP BVD viruses (NADL and Osloss strains). - KEY wORDs: BVDV, cytopathogenicity, pestivirus, RTPCR.
\end{abstract}

J. Vet. Med.Sci. 59(5): 361-370, 1997

Bovine viral diarrhea (BVD) virus, a small enveloped RNA virus, is the prototype member of the genus Pestivirus of the Flaviviridae [11]. BVD virus has a single-stranded RNA genome of positive polarity which is approximately 12.5 kilobases $(\mathrm{kb})$ in length $[4,8,26]$. Two biotypes of $\mathrm{BVD}$ virus, cytopathogenic (CP) and non-cytopathogenic (NCP), can be distinguished on the basis of their effect on cultured cells. Biochemical differences between biotypes occur in the nonstructural protein, $\mathrm{p} 125$, which is processed to proteins p54 and p80 by CP BVD viruses [10]. However, the expression of a p80 is not found after infection of cells with NCP BVD viruses. The most severe clinical manifestation of BVD virus infection in cattle is a mucosal disease which shows a mortality of almost 100 percent. Recent studies indicated that early fetal infection with NCP BVD virus leads to persistent viremia, immunotolerance and a failure to develop antibodies. Persistently viremic animals are infected with NCP BVD virus only, whereas those developing mucosal disease are infected with both NCP and CP BVD viruses [1, 2]. Though field isolates of the BVD virus vary in their antigenicity, antigenic similarity has been shown between $\mathrm{CP}$ and NCP viruses in natural outbreaks of mucosal disease $[6,16]$. Comparison of the genomic sequences of the two strains of CP BVD virus, NADL [4] and Osloss [26] led to the identification of insertions in the BVD virus genome [5]. The amino acid sequences encoded by the nucleotide sequence of insertions were highly homologous to cellular sequences [20]. Accordingly, it was

* Correspondence to: Fukusho, A., National Institute of Animal Health, Department of Exotic Diseases, 6-20-1, Josui-honcho, Kodaira, Tokyo 187, Japan. proposed that a NCP BVD virus mutated to a $\mathrm{CP} B \mathrm{BV}$ virus by taking up cellular sequences during a recombination event in persistently infected animals [21, 22]. This hypothesis, however, was challenged by observations that some CP BVD viruses lacked the insertion in their genomes $[7,9,12]$. Therefore, the understanding of the cytopathogenicity of the BVD virus seems far from complete. Recently, NCP BVD viruses were isolated from CP BVD virus stocks and each virus stock of CP BVD virus contained simultaneously two kinds of NCP BVD viruses showing a different manner of interference [24]. It was speculated that the mutation from the CP biotype to the NCP biotype occurred during the propagation of CP BVD viruses in vitro.

This paper deals with the possibility that the reversion of BVD virus from CP biotype to NCP biotype is caused by the deletion of cellular mRNA insertion in viral genome of CP BVD viruses; NADL and Osloss strains.

\section{MATERIALS AND METHODS}

Viruses and cells: The NADL [13] and Osloss strains [26] of CP BVD virus and derivative NCP BVD viruses (NADL-END $^{+}$, NADL-END ${ }^{-}$, Osloss-END ${ }^{+}$and Osloss$\mathrm{END}^{-}$strains) newly isolated from plaque cloned NADL and Osloss strains in our laboratory were used in this study. The NADL strain originated from the American Type Culture Collection (Rockville, MD, U.S.A.), and the Osloss strain was kindly provided by Prof. B. Liess, Institute for Virology, Hannover Veterinary School, Germany. Stock viruses were propagated in bovine testicle (BT) cell cultures and stored at $-80^{\circ} \mathrm{C}$. The BT cells were grown in Eagle's minimum essential medium (MEM) containing $10 \%$ fetal 
bovine serum (FBS). The BT cells and FBS were tested by the RT-PCR method [14] and found free of adventitious BVD virus. FBS was confirmed to be free of antibody against BVD virus by viral neutralization tests and was treated with gamma-irradiation before use. The Nose strain [18] of CP BVD virus and the New Jersey serotype strain of vesicular stomatitis virus (VSV) were used as challenge viruses for the reverse plaque formation (RPF) method [24]. The Miyadera strain of Newcastle disease virus (NDV) was used for the END method [17, 19].

Plaque formation of $C P B V D$ virus: Plaque assay was used for detection, titration and cloning of CP BVD virus. $\mathrm{CP}$ BVD viruses were diluted in ten fold steps, and $0.2 \mathrm{ml}$ of each dilution was inoculated onto confluent BT cell monolayers grown in $60 \mathrm{~mm}$ plastic petri dishes. The virus adsorption was done at $37^{\circ} \mathrm{C}$ for $1 \mathrm{hr}$ and then the inoculum was aspirated. The infected cells were covered with $5 \mathrm{ml}$ of methylcellulose overlay medium consisting of $1.5 \%$ methylcellulose in MEM containing 2\% FBS. The dishes were then held at $37^{\circ} \mathrm{C}$ for 5 days in a $5 \% \mathrm{CO}_{2}$ incubator. The cultures were fixed with methanol and stained with crystal violet solution for counting of plaques. For plaque cloning, a single plaque developed in the highest dilution was carefully selected and suspended with $1 \mathrm{ml}$ of MEM.

$R P F$ method and isolation of NCP BVD virus from $C P$ $B V D$ virus: The RPF method with the Nose strain of $C P$ BVD virus (Nose-RPF) or VSV (VSV-RPF) as a challenge virus was used for detection, titration and isolation of $\mathrm{NCP}$ BVD virus according to the method of Nakamura et al. [24]. For the isolation of NCP BVD virus, the cells composing a single reverse plaque were collected by trypsinization and then the Nose strain or VSV used as challenge viruses were neutralized with antiserum against each virus. The cells were washed and suspended with MEM and then frozen and thawed three times. The supernatant was used for the isolation of the NCP BVD virus. The cloning procedure by limiting dilution was repeated three times to obtain a pure clone of the NCP BVD isolate.

END method: To determine whether the END phenomenon was induced by newly isolated NCP BVD viruses, the END method [17] was used.

Interference test: To determine whether the homologous or heterologous interference was induced by newly isolated NCP BVD viruses, the interference test was used. The suspension of BT cells was inoculated with NCP BVD virus and 4 days later the cells were challenged with a homologous virus (the Nose strain of CP BVD virus) or a heterologous virus (VSV). Control cultures were challenged in parallel. The results were read 3 days after the challenge inoculation.

Template viral RNA for RT-PCR: Viral RNA was extracted from the supernatant of BVD virus infected BT cell cultures by the acid guanidinium-phenol-chloroform (AGPC) method [3]. After ethanol precipitation, viral RNA was suspended in $0.2 \%$ diethylpyrocarbonate-treated water to prevent degradation of RNA.

Oligonucleotide primers: Eight oligonucleotide primers were synthesized on a ABI DNA synthesizer (Applied Biosystems, Inc. Foster City, CA, U.S.A.) using the phosphoamidite method. Oligonucleotide primers were chosen according to the cDNA sequence of NADL strain [4] and Osloss strain [26]. Primers were selected in the parts encompassing the insertions located in a region encoding for a nonstructural p 125 polypeptide and a highly conserved 5' non-coding region of the BVD virus. The sequences of the primers used are listed in Table 1.

$R T-P C R$ : RT-PCR were performed using DNA Thermal Cycler and the GeneAmp ${ }^{\circledR}$ RNA PCR Kit (Perkin-Elmer Cetus, Norwalk, CT., U.S.A.). The procedure followed was that indicated by the manufacturer's manual. The RT-PCR products were analyzed by electrophoresis on a $2 \%$ agarose gel and were visualized with ethidium bromide under UV light.

Nucleotide sequencing: The RT-PCR product was isolated from a $2 \%$ agarose gel and was cloned into the PstI-digested pGEM 3Z (Promega Co., U.S.A.) plasmid vector according to standard procedures. Dideoxy sequencing was carried out using Sequenase version 2.0 (Toyobo Co., Japan). Computer analysis of sequence data was performed with DNASIS software (Hitachi, Japan).

Table 1. Nucleotide sequence and location on the NADL and the Osloss genome of the synthetic oligonucleotide primers used

\begin{tabular}{|c|c|c|}
\hline Primer & Nucleotide sequence & Location \\
\hline \#1 & (5')GCTACTGCAGACTGCATAATATGCACTGTATGTG & $4833-4856^{a)}$ \\
\hline \#4 & (5')GCTACTGCAGCTTACACACGGCAGGCCCCCTTAGG & $5416-5440^{\mathrm{a})}$ \\
\hline NL1 & (5’)GCTACTGCAGATGTGCAGCCGATGCCAG & $4994-5011^{\text {a) }}$ \\
\hline NL2 & (5')GCTACTGCAGCATCCGTGAACCAAATGA & $5246-5263^{\text {a) }}$ \\
\hline$\# 05$ & (5')GCTA $\underline{\overline{C T G C A G G A C C C T T C A G G C A G G A A C A T A G C G G ~}}$ & $4991-5015^{\text {b) }}$ \\
\hline \#06 & 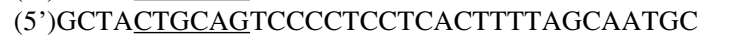 & $5508-5532^{\mathrm{b})}$ \\
\hline \#7 & (5')GCTACTGCAGATCCCTCTCAGCGAAGGCCG & 74-93 \\
\hline \#8 & (5')GCTA $\underline{\text { CTGCAGCAGCAGAGATTTTTAGTAGCAATAC }}$ & $351-375^{\mathrm{a}}$ \\
\hline
\end{tabular}

The underlined sequence indicates the restriction site of PstI.

a) Nucleotide numbers are based on the NADL genome (Collett et al. 1988).

b) Nucleotide numbers are based on the Osloss genome (Renard et al. 1987). 


\section{RESULTS}

Detection of NCP BVD viruses from the cloned CP BVD virus samples on each cloning step: The virus cloning of CP BVD viruses was done a total of 6 times by two methods. The CP BVD virus NADL and Osloss strains were first cloned 3 times by limiting dilution method on tube cell cultures and further cloning was carried out by 3 successive plaque isolations. In order to examine the presence of NCP BVD viruses at each cloning step of CP BVD viruses, each cloned virus sample was tested by the general plaque formation, Nose-RPF and VSV-RPF methods. The CP BVD virus titers of samples after the third cloning by limiting dilution with tube cell cultures showed $1.8 \times 10^{5}$ plaque forming unit (PFU)/0.2 ml (NADL strain) and $3.5 \times 10^{5}$ $\mathrm{PFU} / 0.2 \mathrm{ml}$ (Osloss strain). Whereas, the virus titers of samples from a single plaque after the first, second and third plaque cloning showed approximately $10^{3} \mathrm{PFU} / 0.2 \mathrm{ml}$ level for both NADL and Osloss strains. The virus titer of stock viruses propagated once in BT cell cultures after the third plaque cloning was approximately $10^{6}$ to $10^{7} \mathrm{PFU} / 0.2$ $\mathrm{m} l$ level for both strains. The NADL strain cloned 3 times by limiting dilution with tube cell cultures contained NCP BVD viruses which interfered with the Nose strain and VSV. As shown in Table 2, the virus titers of NCP BVD virus by means of Nose-RPF and VSV-RPF methods were $1.5 \times 10^{3}$ $\mathrm{PFU} / 0.2 \mathrm{~m} l$ and $2.0 \times 10^{2} \mathrm{PFU} / 0.2 \mathrm{~m} l$ which are approximately 100 or 1,000 times lower than the ordinary plaque forming titer of this cloned CP BVD virus, respectively. The NCP BVD viruses, however, were not detected from a single plaque through 3 plaque cloning steps of CP BVD NADL strain. Whereas, the NCP BVD viruses which interfered with Nose strain or VSV were detected again at low ratios by Nose-RPF and VSV-RPF methods in plaque cloned NADL strain which was propagated once in BT cell cultures. The virus titer of NCP BVD virus detected by the Nose-RPF and VSV-RPF methods was $1.5 \times 10^{5}$ $\mathrm{PFU} / 0.2 \mathrm{~m} l$ and $3.0 \times 10^{4} \mathrm{PFU} / 0.2 \mathrm{~m} l$ which are about 100 or 1,000 times lower than the virus titer of CP BVD virus in plaque cloned NADL strain, respectively.

The Osloss strain was cloned by the same way the NADL strain. After clonings (total 6 times) of the Osloss strain of CP BVD virus, NCP BVD viruses were also detected at low ratios, similar to the results of the NADL strain in the cloned virus sample of Osloss strain, by the Nose-RPF and VSVRPF methods.

Characteristic of the isolates: NCP BVD viruses were isolated by the RPF method from the final plaque cloned NADL and Osloss strains. To check their characteristics, these viruses were examined as to whether they caused interference or END phenomena. The results are shown in Table 3. BT cell cultures infected with the isolated NCP BVD viruses showed no CPE after challenge with the Nose strain of CP BVD virus. However, by means of the END method, these viruses were divided into two viruses: END phenomenon positive $\left(\mathrm{NADL}^{-E_{N}{ }^{+}, \text {Osloss-END }}{ }^{+}\right.$) and END phenomenon negative (NADL-END', Osloss-END ${ }^{-}$).
Table 2. Quantitative assay of NADL strain of BVD virus by the plaque and RPF methods at each cloning step

\begin{tabular}{lccc}
\hline & \multicolumn{3}{c}{ Virus titer (PFU/0.2 ml) } \\
\cline { 2 - 4 } Virus samples & Plaque $^{\mathrm{a})}$ & Nose-RPF & VSV-RPF $^{\mathrm{c})}$ \\
\hline 3rd limiting dilution & & & \\
1st plaque cloning $^{\mathrm{d})}$ & $3.8 \times 10^{5}$ & $1.5 \times 10^{3}$ & $2.0 \times 10^{2}$ \\
2nd plaque cloning $\left.^{\mathrm{f}}\right)$ & $3.2 \times 10^{3}$ & Not detected & Not detected \\
3rd plaque cloning) $^{\mathrm{g})}$ & $3.4 \times 10^{3}$ & Not detected & Not detected \\
NADL BT-1 $^{\mathrm{h})}$ & $1.4 \times 10^{7}$ & $1.5 \times 10^{5}$ & $3.0 \times 10^{4}$ \\
\hline
\end{tabular}

a) Virus titer calculated from ordinary plaques which were formed by $\mathrm{CP}$ virus.

b) Virus titer calculated from reverse plaques which were formed by NCP virus after challenge with Nose strain of BVDV.

c) Virus titer calculated from reverse plaques which were formed by NCP virus after challenge with VSV.

d) Virus harvested from cell culture cloned by the third limiting dilution with tube cell cultures.

e), f), g) Virus obtained from a single plaque which developed in the highest dilution at each plaque cloning step.

h) Virus stock progpagated once in BT cells after third plaque cloning.

Table 3. Characterization of the isolated NCP BVD viruses

\begin{tabular}{lcccc}
\hline \multirow{2}{*}{ Virus } & \multicolumn{2}{c}{ Interference method } & & END method \\
\cline { 2 - 3 } & CP BVDV & VSV & & NDV \\
\hline MADL-END $^{+}$ & - a) & $+{ }^{\text {b) }}$ & & + \\
MADL-END $^{-}$ & - & - & & - \\
Osloss-END $^{+}$ & - & + & & + \\
Osloss-END $^{-}$ & - & - & & - \\
Control & + & + & & - \\
\hline
\end{tabular}

CP BVDV, VSV and NDV were used as a challenge virus.

a) CPE negative.

b) CPE positive.

NADL-END $^{+}$and Osloss-END ${ }^{+}$strain infected BT cell cultures showed CPE after challenge with NDV and VSV. In contrast, BT cell cultures infected with NADL-END- and Osloss-END- strains showed no CPE after challenge with NDV and VSV. The END phenomenon negative viruses interfered completely with CP BVD virus, NDV and VSV, even though a high titer of these viruses was used as a challenge virus.

Electrophoretic analysis of the PCR products of $C P$ and $N C P$ strains: To investigate the existence of cellular mRNA insertion, the region corresponding to the insertions of cellular mRNA in two real pairs of homologous $\mathrm{CP}$ and NCP strains (NADL, NADL-END ${ }^{+}$, NADL-END ${ }^{-}$and Osloss, Osloss-END ${ }^{+}$, Osloss-END ${ }^{-}$) was amplified by RTPCR. A gel electrophoresis of the fragment amplified by \#1/\#4 primers for CP NADL, derivative NCP NADL-END ${ }^{+}$ and NADL-END ${ }^{-}$strains is shown in Fig. 1. The PCR product of primers \#1 and \#4 should be a 608 -base pairs (bp) fragment encompassing nucleotides 4833-5440 of the NADL sequence. A smaller product is expected if the viral genome lacks cellular mRNA insertions. A specific 


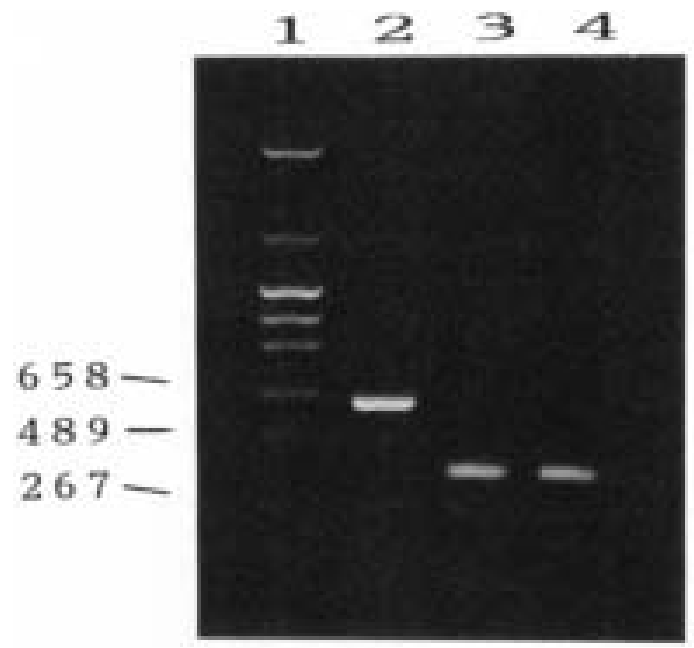

Fig. 1. Electrophoretic analysis of the RT-PCR amplification products derived from NADL, NADL$\mathrm{END}^{+}$and NADL-END' strains of BVD virus using \#1 and \#4 primers. Lane 1: Size marker; Lane 2: NADL; Lane 3: NADL-END+; Lane 4: NADL-END'.

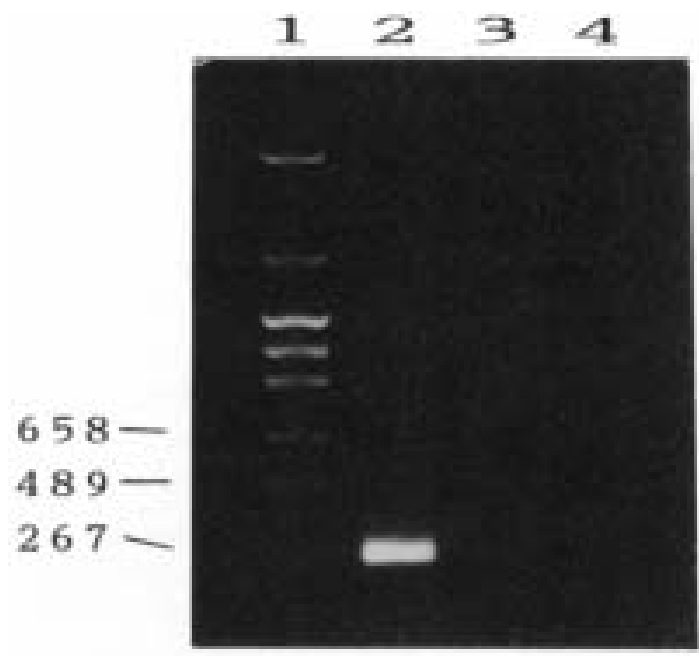

Fig. 2. Electrophoretic analysis of the nested PCR amplification products derived from RT-PCR products of NADL strain of BVD virus using NL1 and NL2 primers. Lane 1: Size marker; Lane 2: NADL; Lane 3: NADL-END ${ }^{+}$; Lane 4: NADL-END

fragment of the expected size was observed for the biologically cloned NADL strain (Fig. 1, lane 2). However, the fragments of NADL-END ${ }^{+}$and NADL-END ${ }^{-}$strains (Fig. 1, lane 3 and 4) were smaller than that of cloned NADL strain, and only the nested PCR product of primers NL1 and NL2 was observed with the RT-PCR product of NADL strain (Fig, 2, lane 2). Of the other primer pairs for the Osloss strain, \#05/\#06 gave an amplified cDNA fragment of the expected size (542-bp) with the biologically cloned Osloss strain (Fig. 3, lane 2). Analysis of amplification products of Osloss-END ${ }^{+}$and Osloss-END ${ }^{-}$indicated the

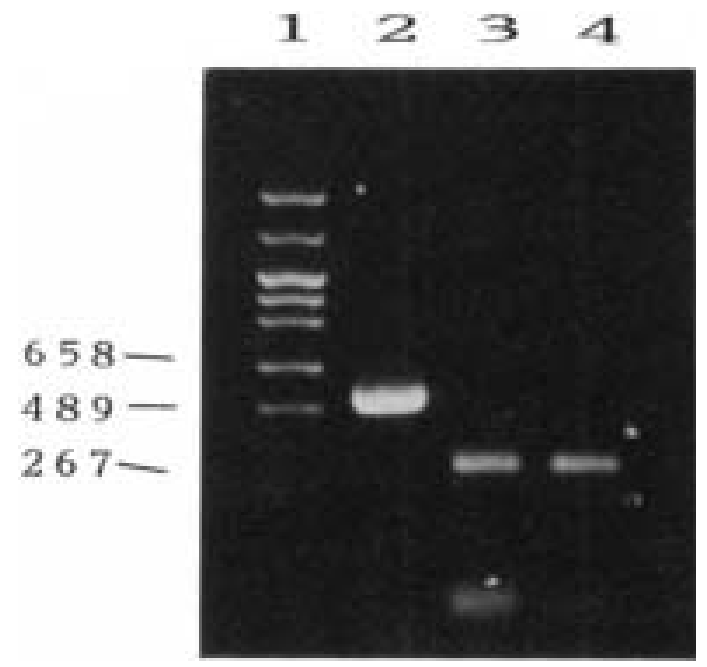

Fig. 3. Electrophoretic analysis of the RT-PCR amplification products derived from Osloss, Osloss$\mathrm{END}^{+}$and Osloss-END ${ }^{-}$strains of BVD virus using \#05 and \#06 primers. Lane 1: Size marker; Lane 2: Osloss; Lane 3: Osloss-END+; Lane 4: Osloss-END'.

presence of cDNA bands of smaller sizes (Fig. 3, lane 3 and 4$)$. The primer pair, \#7/\#8 successfully gave an amplified cDNA fragment of the expected size with all 6 strains tested (Fig. 4). No amplification was detected with RNA extracted from BT cell cultures not infected with BVD virus.

Nucleotide sequence of the region flanking the cellular $m R N A$ insertion: The cDNA products amplified by RT-PCR from viral genome of the $\mathrm{CP}$ viruses (NADL and Osloss strains after plaque cloning) and the NCP viruses (NADL$\mathrm{END}^{+}, \mathrm{NADL}^{-\mathrm{END}^{-} \text {and Osloss-END }}{ }^{+}$, Osloss-END ${ }^{-}$as progenies of each $\mathrm{CP}$ parent virus) were cloned into pGEM $3 Z$ plasmid vector for sequencing. The nucleotide sequences of each clone were determined and compared with the published sequences of NADL and Osloss strains.

The comparison of nucleotide sequences and their deduced amino acids sequences among the original NADL strain (the sequence published by Collett et al. [4]), NADL plaque cloned strain, NADL-END ${ }^{+}$and NADL-END' are shown in Figs. 5 and 6. The nucleotide sequence and its deduced amino acids sequence of the plaque cloned NADL strain showed complete homology to that of NADL original strain. However, the insertion of cellular mRNA integrated in the viral genome of NADL strain $(270 \mathrm{bp}$; 5'ATGTGC......CGGATG3') was completely and exactly deleted from the viral genome of NADL-END ${ }^{+}$and NADLEND- NCP viruses (Fig. 5). There were no nucleotide differences between NADL-END ${ }^{+}$and NADL-END', whereas, a small number of nucleotides on the sequences of both NADL-END ${ }^{+}$and NADL-END- were exchanged in the region surrounding the insertion of cellular mRNA of $\mathrm{CP}$ NADL strain. The amino acid residues on both NADLEND $^{+}$and NADL-END- were exchanged from Phenylalanine to Tyrosine (at position 1534) and also from Valine to Isoleucine (at position 1651) when compared with 

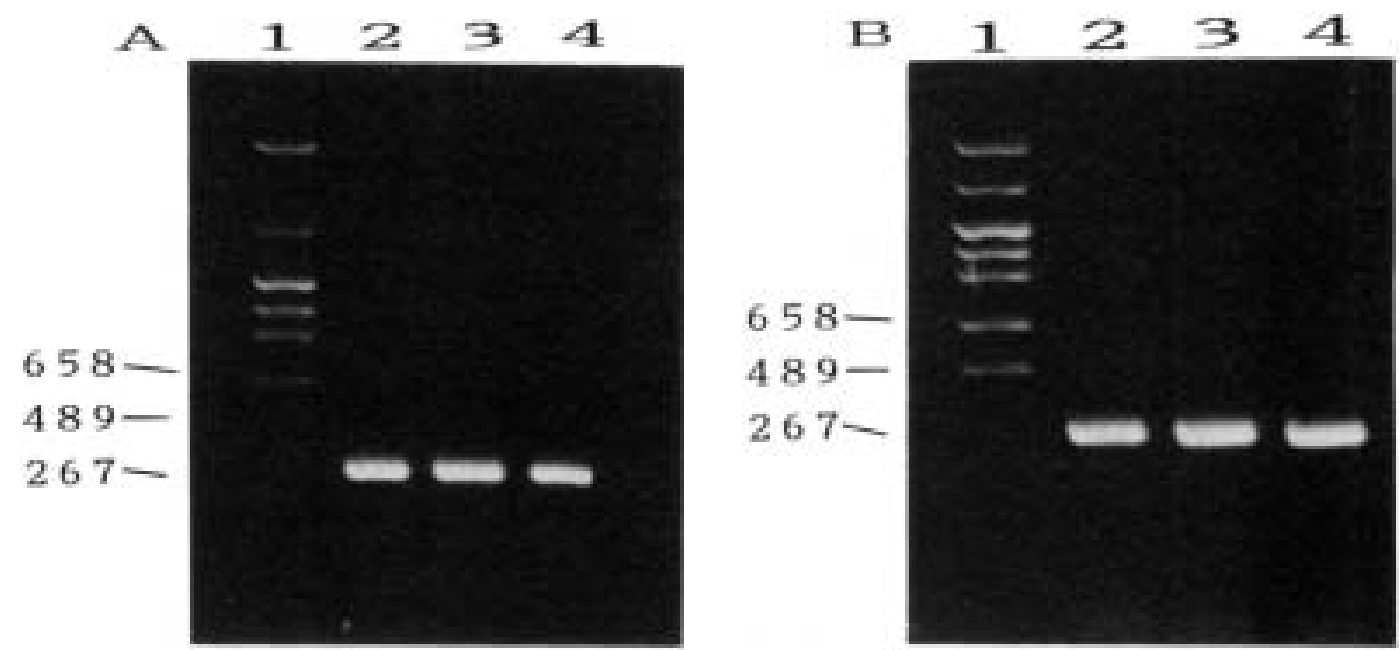

Fig. 4. Electrophoretic analysis of the RT-PCR amplification products derived from CP and NCP BVD virus genomes using \#7 and \#8 primers. (A) Lane 1: Size marker; Lane 2: NADL; Lane 3: NADL-END ${ }^{+}$; Lane 4: NADL-END', (B) Lane 1: Size marker; Lane 2: Osloss; Lane 3: Osloss-END ${ }^{+}$; Lane 4: Osloss-END'.

the CP NADL strain (Fig. 6).

The comparison of nucleotide sequences and their deduced amino acids sequences among the original Osloss strain (the sequence published by Renard et al. [26]), Osloss strain plaque cloned, Osloss-END ${ }^{+}$and Osloss-END- are shown in Figs. 7 and 8. The nucleotide sequence and its amino acids sequence of the plaque cloned Osloss strain showed complete homology to that of original Osloss strain except for the exchange of $1 \mathrm{bp}$ of nucleotide (T to A; at the position of 5314) and 1 amino acid residue (Serin to Threonine). However, the insertion of cellular mRNA integrated in the viral genome of Osloss strain (228 bp; 5'ATGCAG......GGTAGT3') was completely and exactly deleted from the viral genome of Osloss-END ${ }^{+}$and OslossEND $^{-}$NCP viruses (Fig. 7). There were no nucleotide differences between the Osloss-END ${ }^{+}$and Osloss-END NCP viruses, however, nucleotide exchanges were scattered in the region surrounding the insertion of cellular mRNA of Osloss CP strain when compared with the sequence of Osloss CP strain. The amino acid residues on both OslossEND $^{+}$and Osloss-END ${ }^{-}$NCP viruses were exchanged at 4 sites compared with that of the Osloss CP strain (Fig. 8).

\section{DISCUSSION}

The BVD viruses were divided into two biotypes, namely, CP BVD virus and NCP BVD virus. Furthermore, we identified that NCP BVD viruses can be divided into two different groups by the manner of their interference; that is, NCP BVD virus $\left(E^{+} D^{+}\right.$) leads to only homologous interference and NCP BVD virus (END') shows not only homologous but also heterologous interference. The former NCP BVD virus $\left(\mathrm{END}^{+}\right)$showed the END phenomenon but not the latter NCP BVD virus (END-) [24]. The RPF method based on the intrinsic interference, could be applicable for the detection of different NCP BVD viruses by selection of a challenge virus. When the RPF method was performed using the Nose strain of CP BVD virus (homologous virus against NCP BVD virus) as a challenge virus, reverse plaques were produced by both $\mathrm{END}^{+}$and END- NCP BVD viruses. However, reverse plaques were developed only by the END- NCP BVD virus when VSV (heterologous virus against NCP BVD virus) was used as a challenge virus [24].

Previously we reported that two different NCP BVD viruses were isolated from $3 \mathrm{CP} B V D$ virus stocks by the RPF method and the dominant CP BVD virus and the newly isolated NCP BVD viruses were antigenically indistinguishable [24]. However, the origin of NCP BVD viruses contaminating $\mathrm{CP} B \mathrm{BD}$ virus stocks has not been identified. In our previous paper, we speculated that the mutation from the CP biotype to the NCP biotype occurs during the propagation of CP BVD virus. To confirm this speculation, biological cloning of the CP BVD virus was carried out and we examined whether the NCP BVD viruses were reproduced in plaque cloned CP BVD virus samples using the RPF method. The result was that NCP viruses were detected at a low ratio in CP BVD virus samples in spite of a total of 6 clonings. At each plaque cloning step of CP BVD virus (NADL strain), a single plaque which developed at the highest dilution of the virus sample was chosen for the next virus cloning. At the same time, samples from the single plaque were tested by the RPF method to determine whether NCP BVD viruses existed or not. The result was that NCP BVD viruses were not detected in any single plaque at each cloning step. However, NCP BVD viruses were again detected at a low ratio again by RPF methods when such a cloned virus sample was propagated on a large scale in BT cell culture. This phenomenon suggests that NCP BVD viruses are produced at a low ratio during propagation of the CP BVD virus. It seems that this is a real phenomenon because the populations 
4904

NADL pb GGGAAGCCGA TAACGTGTGG GATGTCGCTA GCAGATTTTG AAGAAAGACA NADL cl cl

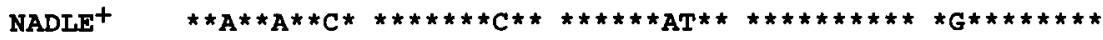

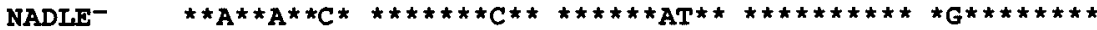

4954

NADL $\mathrm{pb}$ NADL $\mathrm{cl}$

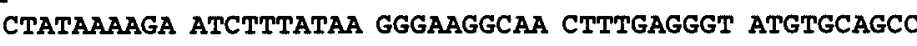

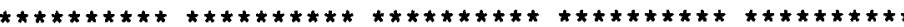
NADLE $E^{+}$

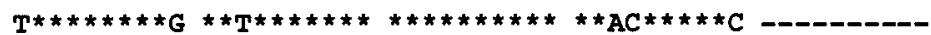
NADLE-

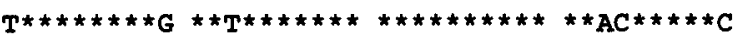
5004

NADL pb GATGCCAGGG AAAGCATAGG AGGTTTGAAA TGGACCGGGA ACCTAAGAGT NADL Cl $\quad$ C NADLE $E^{+}$

NADIE-

5054

NADL pb GCCAGATACT GTGCTGAGTG TAATAGGCTG CATCCTGCTG AGGAAGGTA NADL cl $\quad$ ck NADLE ${ }^{+}$- NADLE-

5104

NADL Pb CTTTTGGGCA GAGTCGAGCA TGTTGGGCCT CAAAATCACC TACTTTGCGC

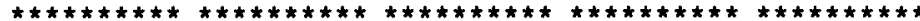

NADLE $E^{+}$

NADLE-

5154

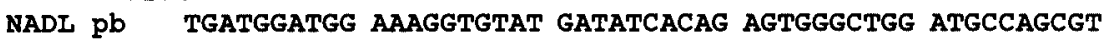
NADL Cl $\quad$ cl

NADLE ${ }^{+} \quad$ -

5204

NADL pb GTGGGAATCT CCCCAGATAC CCACAGAGTC CCTTGTCACA TCTCATTTGG

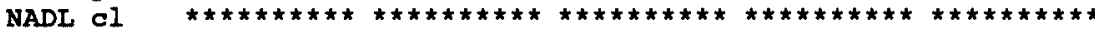
NADLE ${ }^{+}$

NADIE-

5254

NADL pb TTCACGGATG CCTTTCAGGC AGGAATACAA TGGCTTTGTA CAATATACCG

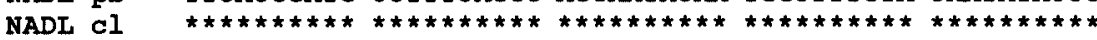

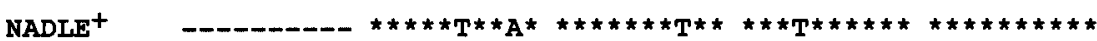

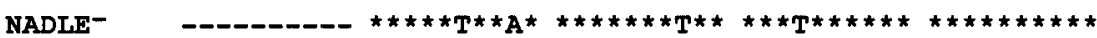
5304

NADL pb CTAGGGGGCA ACTATTTCTG AGAAACTTGC CCGTACTGGC AACTAAAGTA

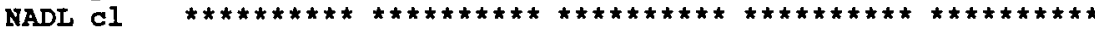

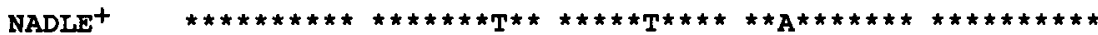

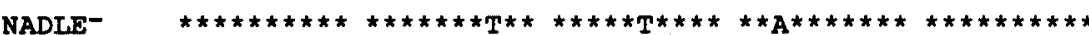

5354

NADL Pb AAAATGCTCA TGGTAGGC

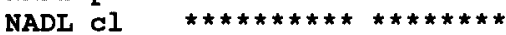

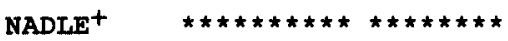

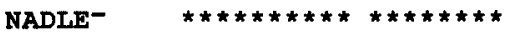

Fig. 5. Comparison of the nucleotide sequences of the region of the BVD virus strain NADL genome containing the host cell-derived insertions. The numbers correspond to the published NADL sequence. Abbreviations used for BVD virus strains: NADL pb, published sequence (Collett et al., 1988); NADL cl, plaque cloned NADL; NADLE ${ }^{+}$, NADL-END ${ }^{+}$; NADLE; ${ }^{-}$NADL-END- 


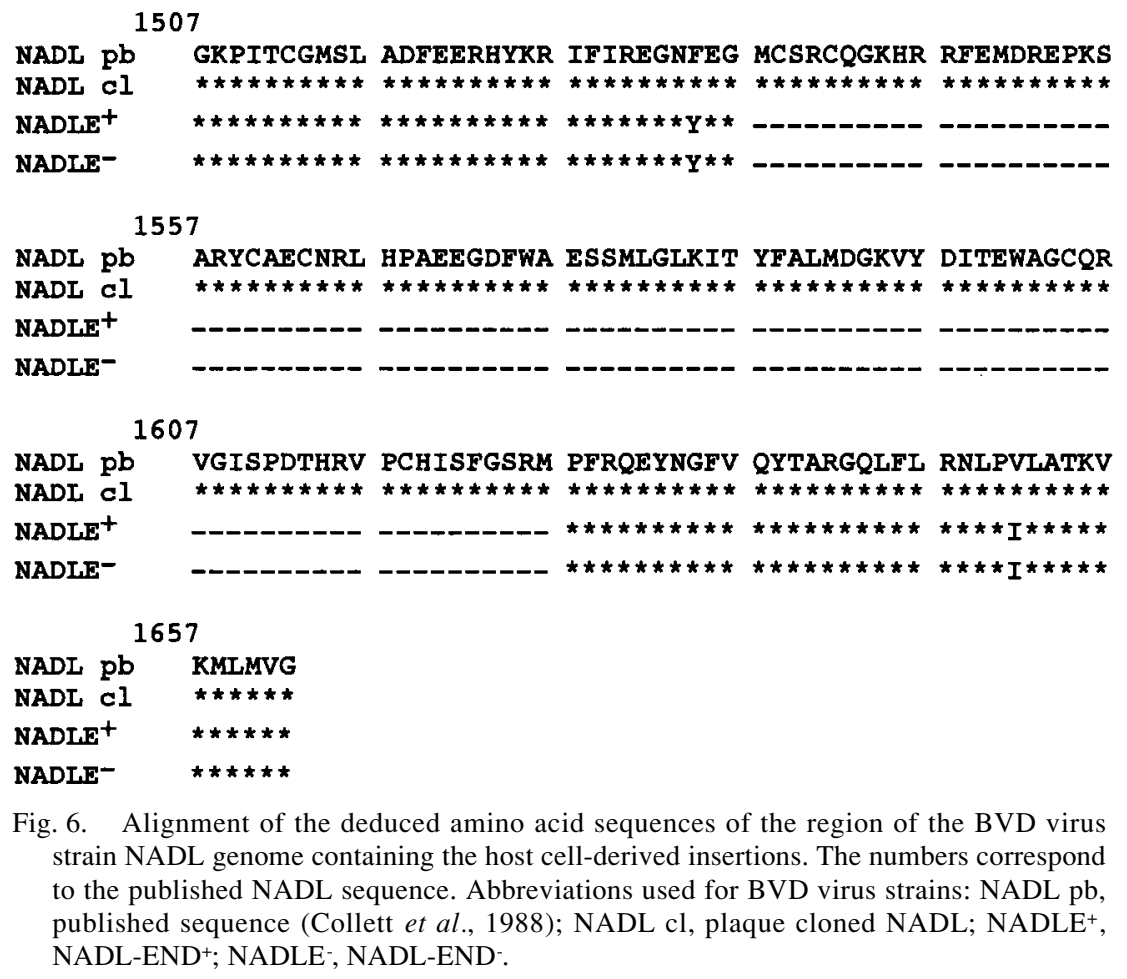

of CP and NCP BVD viruses were checked at each cloning step by both the general plaque formation method for the detection of a major population of CP BVD virus, and the RPF method for detection of a minor population of NCP $\mathrm{BVD}$ viruses. If there is no method for the detection and isolation of minor NCP BVD viruses, it will not be possible to confirm this phenomenon. On the other hand, it was confirmed that the NCP BVD viruses isolated in this experiment were not contaminants from BT cells, FBS and medium because they were checked by RT-PCR and found to be free of BVD virus, and especially because FBS was gamma-irradiated. The NCP BVD viruses detected by the RPF method were not defective interfering particles which were recently reported by Tautz et al. [28] since they are infectious and can propagate well in BT cell cultures. It has also been demonstrated that the NCP biotype virus was detected in CP BVD virus samples by immunoplaque assay after cloning of the Indiana 'Gillette' strain of CP BVD virus [15]. These results indicate that the NCP BVD viruses were produced at a low ratio as progeny of CP BVD virus. This phenomenon can be comprehended through the general fact that the CPE of CP BVD virus is weakened by continuous virus passages with high multiplicity of infection; that is, the population of the NCP BVD viruses increases after multi-passages of CP BVD viruses and then the NCP BVD viruses interfere with the development of CPE caused by the CP BVD viruses.

To elucidate why NCP BVD viruses are produced from the CP BVD virus, we analyzed the existence of the insertion of cellular mRNA integrated on the region p125 in the genome of NADL and Osloss strains. In this experiment, the CP and NCP BVD viruses with real parent-progeny relationships were isolated after 6 clonings of CP BVD viruses (NADL and Osloss strains). Using these $\mathrm{CP}$ and NCP BVD viruses, the existence of the sequence of insertion in the region encoding p125 between CP and NCP BVD viruses was analyzed by RT-PCR and sequencing. We confirmed that the sequences of cellular mRNA insertion of CP BVD viruses were completely and exactly deleted from both $\mathrm{END}^{+}$and $\mathrm{END}^{-} \mathrm{NCP}$ BVD viruses which were real progeny of CP BVD viruses, namely, NADL and Osloss strains. Therefore, it is presumed that BVD viruses, such as NADL and Osloss strains, revert from CP biotype to NCP biotype by deletion of the integrated host cell mRNA in the viral genome following propagation of CP BVD virus.

The complete nucleotide sequences of the NADL and Osloss strains of CP BVD viruses have been published and the size of the viral genome has been confirmed as $12.5 \mathrm{~kb}$ $[4,26]$. When these sequences were aligned for comparison with the BVD viruses, the NADL and Osloss strains were found to have insertions of 270 and $228 \mathrm{bp}$, respectively, of cellular mRNA in the predicted coding region for p125 nonstructure protein $[4,8,20-22,26]$. The sequence of the insertion in the viral genome of NADL strain showed $99 \%$ homology with a host cellular mRNA encoding for an unknown function [4]. That of the Osloss strain was identified as a gene corresponding to an ubiquitin like protein [26]. Generally, CP BVD viruses have only been isolated at the same time as isolation of NCP BVD virus from cattle suffering from mucosal disease $[1,2]$. Meyers et al. [21-23] proposed the hypothesis that the CP BVD virus develops in cattle suffering from mucosal disease 
5071

\begin{tabular}{|c|c|c|c|c|c|}
\hline $\begin{array}{ll}\text { Osloss } & \mathrm{pb} \\
\text { osloss } & \mathrm{cl}\end{array}$ & $\begin{array}{l}\text { GCAACCAAAG } \\
* * * * * * * * * *\end{array}$ & $\begin{array}{l}\text { TAAAAATGCT } \\
* * * * * * * * * *\end{array}$ & $\begin{array}{l}\text { TATGGTAGGC } \\
* * * * * * * * * *\end{array}$ & $\begin{array}{l}\text { AACCTAGGGG } \\
* * * * * * * * * *\end{array}$ & $\begin{array}{l}\text { TAG } \\
* * *\end{array}$ \\
\hline & $* * * * * \mathrm{~T} * * * * *$ & $* * * * * * * * * *$ & $\mathrm{C} * * * * * \mathrm{G} * * *$ & $* * * * * \mathrm{~T} * * \mathrm{~A} *$ & $\mathrm{~A} * * * * * * \mathrm{~T} * *$ \\
\hline & $* * * * * \mathrm{~T} * * * *$ & $* * * * * * * * * * *$ & $\mathrm{C} * * * * * \mathrm{G} * * *$ & $* * * * * \mathrm{~T} * * \mathrm{~A} *$ & $\mathrm{~A} * * * * * * \mathrm{~T} * *$ \\
\hline
\end{tabular}

5121

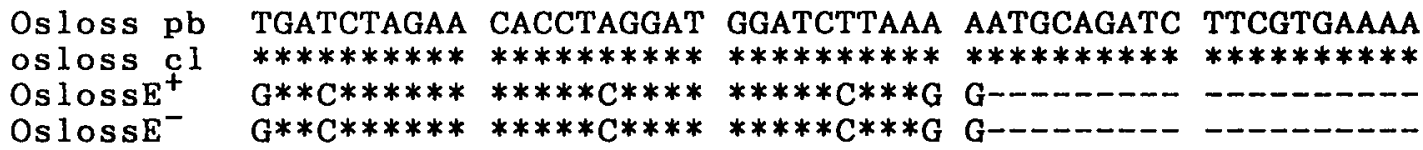

5171

Osloss pb CCCTGACCGG CAAGACCATC ACCCTGGAGg TGGAGCCCAG TGACACCATC osloss cl $* * * * * * * * * * * * * * * * * * * * * * * * * * * * * * * * * * * * * * * * * * * * * * * * * * * *$ Os losse $\mathrm{E}^{+}$ Os lossE
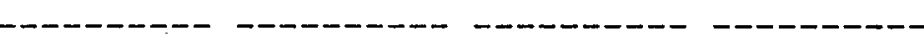

5221

Osloss pb GAGAACGTGA AGGCCAAGAT CCAGGATAAG GAAGGCATTC CCCCTGACCA Osloss cl Osloss $\mathrm{E}^{-}$ $* * * * * * * * * * * * * * * * * * * *$
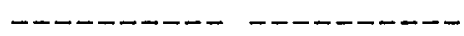
**********

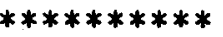
$* * * * * * * * * *$

5271

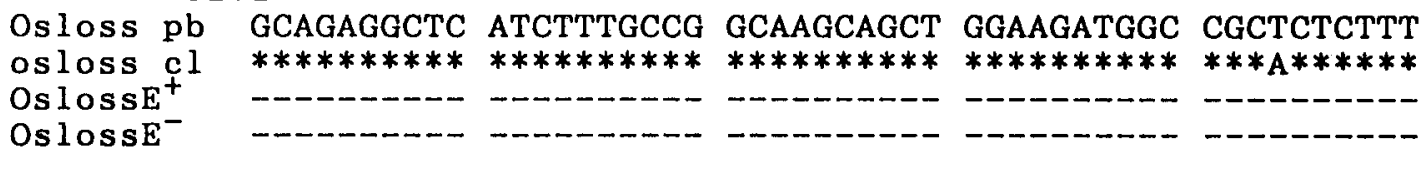
5321

Osloss pb CTGATTACAA CATCCAGAAA GAGTCGACCC TGCACCTGGT CCTCCGTCTG Os loss $\mathrm{E}^{+}$ Osloss $E^{-}$
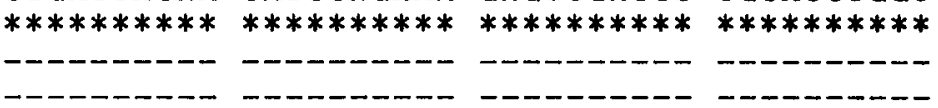
***********

5371

Osloss pb AGGGGTAGTG GGCCTGCCGT GTGCAAAAAG ATTACTGAGC ATGAGAAATG osloss cl $* * * * * * * * * * * * * * * * * * * * * * * * * * * * * * * * * * * * * * * * * * * * * * * * * * * *$ Osloss $\mathrm{E}^{+}$ Os $\operatorname{los} \mathrm{EE}^{-}$

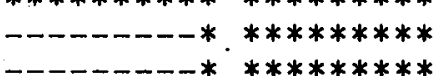
$* * * * * * \mathrm{G} * * * * * \mathrm{C} * * \mathrm{~A} * * * * * \mathrm{C} * * \mathrm{~A} * * * * *$ $* * * * * * \mathrm{G} * * * * * \mathrm{C} * * \mathrm{~A} * * * * * \mathrm{C} * * \mathrm{~A} * * * * *$

5421

Osloss pb CCATGTCAAC ATACTAGACA AATTGACCGC ATTTTTCGGG GTTATGCCAA osloss c1 $1 * * * * * * * * * \quad * * * * * * * * * * \quad * * * * * * * * * * * * * * * * * * * * * * * * * * * * * * *$ Oslos $\mathrm{E}^{+} \quad * * * \mathrm{CA} * * * * * * * * * * * * * \mathrm{~T} * * * \mathrm{C} * \mathrm{~A} * * \mathrm{~T} * * * * * \mathrm{C} * * * * * * \mathrm{~A} * \mathrm{C} * * * * * * *$ Os $\operatorname{los} \mathrm{sE}^{-}$ $* * * \mathrm{CA} * * * * * * * * * * * * * \mathrm{~T} * * * \mathrm{C} * \mathrm{~A} * * \mathrm{~T} * * * * * * \mathrm{C} * * * * * * \quad \mathrm{~A} * \mathrm{C} * * * * * * *$

5471

Osloss pb GAGGTACC

osloss cl $* * * * * * * *$

Os loss $\mathrm{E}^{+} \quad * \mathrm{G} * \mathrm{G}_{\mathrm{G}} * \mathrm{~T}$

Os loss $\mathrm{E}^{-} \quad * \mathrm{G} * * \mathrm{G} * * \mathrm{~T}$

Fig. 7. Comparison of the nucleotide sequences of the region of the BVD virus strain Osloss genome containing the ubiquitin coding insertions. The numbers correspond to the published Osloss sequence. Abbreviations used for BVD virus strains: Osloss pb, published sequence (Renard et al., 1987); Osloss cl, plaque cloned Osloss; OslossE ${ }^{+}$, Osloss$\mathrm{END}^{+}$; OslossE-, Osloss-END-.

through integration of additional RNA in the genome of NCP BVD virus in a recombination process. This hypothesis is supported paradoxically by our result that $\mathrm{CP}$
BVD viruses change to NCP biotype by deletion of the cellular mRNA integrated in the region encoding p125 nonstructural protein. The existence of foreign RNA 

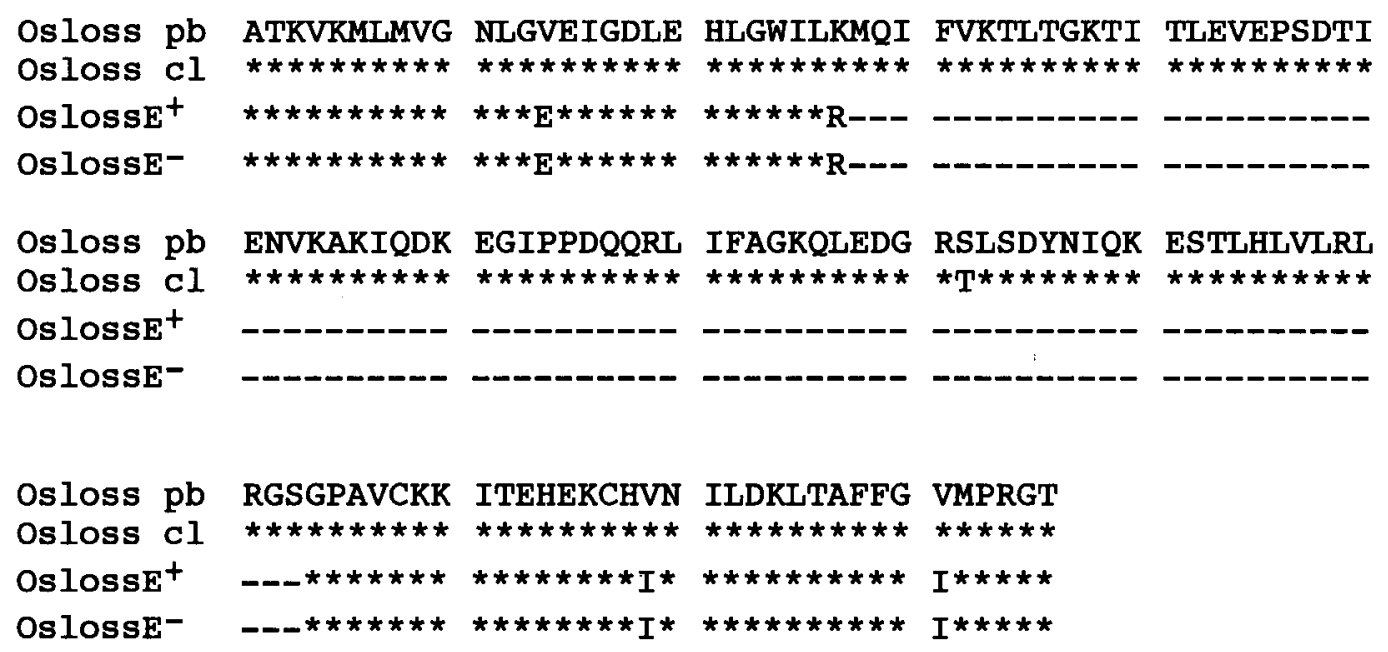

Fig. 8. Alignment of the deduced amino acid sequences of the region of the BVD virus strain Osloss genome containing the ubiquitin coding insertions. Abbreviations used for BVD virus strains: Osloss pb, published sequence (Renard et al., 1987); Osloss cl, plaque cloned Osloss; OslossE ${ }^{+}$, Osloss-END ${ }^{+}$; OslossE-, OslossEND-.

insertion into the portion of the genome encoding for the p125 polypeptide have been reported for several, but not all, CP BVD viruses [7, 9, 12, 20-23, 25]. Therefore, the occurrence of insertion may not be the only mechanism involved in biotypic determination [27]. To elucidate these mechanisms, it will be necessary to analyze the genetic differences between CP and NCP BVD viruses using an infectious viral cDNA clone.

\section{REFERENCES}

1. Bolin, S. R., McClurkin, A. W., Cutlip, R. C., and Coria, M. F.1985. Severe clinical disease induced in cattle persistently infected with noncytopathic bovine viral diarrhea virus by superinfection with cytopathic bovine viral diarrhea virus. Am. J. Vet. Res. 46: 573-576.

2. Brownlie, J ., Clarke, M. C., and Howard, C. J. 1984. Experimental production of fatal mucosal disease in cattle. Vet. Rec. 114: 535-536.

3. Chomczynski, P. and Sacchi, N. 1987. Single-step method of RNA isolation by acid guanidinium thiocyanate-phenol-chloroform extraction. Anal. Biochem. 162: 156-159.

4. Collett, M. S., Larson, R., Gold, C., Strick, D., Anderon, D. K., and Purchio, A. F. 1988. Molecular cloning and nucleotide sequence of the Pestivirus bovine viral diarrhea virus. Virology 165: 191-199.

5. Collett, M. S., Moennig, V., and Horzinek, M. C. 1989. Recent advances in pestivirus research. J. Gen. Virol. 70: 253-266.

6. Corapi, W. V., Donis, R. O., and Dubovi, E. J. 1988. Monoclonal antibody analyses of cytopathic and noncytopathic viruses from fatal bovine viral diarrhea virus infection. $J$. Virol. 62: 2823-2827.

7. De Moerlooze, L., Desport, M., Renard, A., Lecomte, C., Brownlie, J., and Martial, J. A. 1990. The coding region for the 54-kDa protein of several pestiviruses lacks host insertions but reveals a "Zinc finger-like" domain. Virology 177: 812-815.
8. Deng. R. and Brock, K. V. 1992. Molecular cloning and nucleotide sequence of a Pestivirus genome, noncytopathic bovine viral diarrhea virus strain SD-1. Virology 191: 867879.

9. Desport, M. and Brownlie, J. 1991. Molecular characterization of the coding region for the $\mathrm{p} 125$ from homologous BVDV biotypes. Arch. Virol. (Suppl.) 3: 261-265.

10. Donis, R. O. and Dubovi, E. J. 1987. Differences in virusinduced polypeptides in cells infected by cytopathic and noncytopathic biotypes of bovine virus diarrhea-mucosal disease virus. Virology 158: 168-173.

11. Francki, R. I. B., Fauquet, C. M., Knudson, D. L., and Brown, F. 1991. Classification and nomenclature of viruses. Arch. Virol. (Suppl.) 2: 223-233.

12. Greiser-Wilke, I., Haas, L., Dittmar, K., Liess, B., and Moennig,V. 1993. RNA insertion and gene duplication in the nonstructural protein p125 region of pestivirus strains and isolates in vitro and in vivo. Virology 193: 977-980.

13. Gutekunst, D. E. and Malmquist, W. A. 1963. Separation of a soluble antigen and infectious particles of bovine viral diarrhea viruses and their relationship to hog chorela. Can. J. Comp. Med. Vet. Sci. 27: 121-123.

14. Harasawa, R. and Tomiyama, T. 1994 Evidence of pestivirus RNA in human virus vaccines. J. Clin. Microbiol. 32: 1604 1605.

15. Hewicker-Trautwein, M., Liess, B., Frey, H.-R., and Trautwein, G. 1994. Virological and pathological findings in sheep fetuses following experimental infection of pregnant ewes with cytopathogenic-bovine-virus diarrhoea virus. J. Vet. Med. B 41: 264-276.

16. Howard, C. J., Brownlie, J., and Clarke, M. C. 1987. Comparison by the neutralization assay of pairs of non-cytopathogenic and cytopathogenic strains of bovine virus diarrhoea virus isolated from cases of mucosal disease. Vet. Microbiol. 13: 361-369.

17. Inaba, Y., Tanaka, Y., Kumagai, T., Omori, T., Ito, H., and Matumoto, M. 1968. Bovine diarrhea virus. II. END phenomenon: exaltation of Newcastle disease virus in bovine cells infected with bovine diarrhea virus. Jpn. J. Microbiol. 12: 
$35-49$.

18. Kodama, K., Sasaki, N., Fukuyama, S., Izumida, A., and Ishii, F. 1974. Studies on cytopathogenic bovine viral diarrhea virus: Recovery, identification, and properties of the isolated virus. Bull. Nippon Vet. Zootech. Coll. 23: 51-59.

19. Kumagai, T., Shimizu, T., Ikeda, S., and Matumoto, M. 1961. A new in vitro method (END) for detection and measurement of hog cholera virus and its antibody by means of effect of $\mathrm{HC}$ virus on Newcastle disease virus in swine tissue culture. I. Establishment of standard procedure. J. Immunol. 87: 245256.

20. Meyers, G., Rümenapf, T., and Thiel, H.-J. 1989. Ubiquitin in a togavirus. Nature (Lond.) 341: 491.

21. Meyers, G., Rümenapf, T., Tautz, N., Dubovi, E. J., and Theil, H.-J. 1991. Insertion of cellular sequences in the genome of bovine viral diarrhea virus. Arch. Virol. (Suppl.) 3: 133-142.

22. Meyers, G., Tautz, N., Dubovi, E. J., and Thiel, H.-J. 1991. Viral cytopathogenicity correlated with integration of ubiquitin-coding sequences. Virology 180: 602-616.

23. Meyers, G., Tautz, N., Stark, R., Brownlie, J., Dubovi, E. J.
Collett, M. S., and Thiel, H.-J. 1992. Rearrangement of viral sequences in cytopathogenic pestiviruses. Virology 191: 368386.

24. Nakamura, S., Fukusho, A., Inoue, Y., Sasaki, H., and Ogawa, N. 1993. Isolation of different non-cytopathogenic bovine viral diarrhoea (BVD) viruses from cytopathogenic BVD virus stocks using reverse plaque formation method. Vet. Microbiol. 38: 173-179.

25. Qi, F., Ridpath, J. F., Lewis, T., Bolin, S. R., and Berry, E. S. 1992. Analysis of the bovine viral diarrhea virus genome for possible cellular insertions. Virology 189: 285-292.

26. Renard, A., Dina, D., and Martial, J. 1987. Vaccines and diagnostics derived from bovine diarrhea virus. European Patent Application number 86870095.6. Publication number 0208672.

27. Ridpath, J. F., Qi, F., Bolin, S. R., and Berry, E. S. 1994. Natural recombination in bovine viral diarrhea viruses. Arch. Virol. (Suppl.) 9: 239-244.

28. Tautz, N., Thiel, H.-J., Dubovi, E. J., and Meyers, G. 1994. Pathogenesis of mucosal disease: a cytopathogenic pestivirus generated by an internal deletion. J. Virol. 68: 3289-3297. 